\title{
Complete Spontaneous Submucosal Dissection of the Sigmoid Colon
}

\section{C. de la Serna-Higuera ${ }^{1}$, M. I. Martín-} Arribas', S. J. Rodríguez-Gómez ${ }^{1}$, A. Pérez Villoria ${ }^{1}$, C. González del Rey ${ }^{2}$ ${ }^{1}$ Dept. of Gastroenterology, Virgen de la Concha Hospital, Zamora, Spain 2 Dept. of Pathology, Virgen de la Concha Hospital, Zamora, Spain

\section{Corresponding Author}

\section{C. de la Serna-Higuera, M.D.}

Unidad de Digestivo

Hospital "Virgen de la Concha"

Avenida de Requejo 31-33

Zamora 49002

Spain

Fax: $\quad+34-980-548-221$

E-mail: csernah@hotmail.com

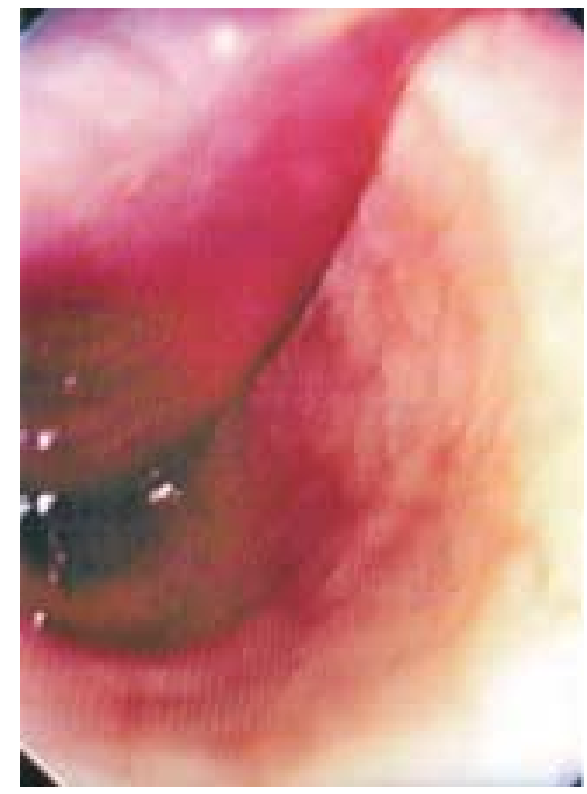

Figure 1 A 73-year-old woman presented with cramps and scant hematochezia. She was otherwise healthy. There was no history of prior illness, drug ingestion, trauma, or foreign-body introduction. The physical examination only showed a large, membranous structure protruding through the anal canal. Laboratory values were within normal limits. Flexible sigmoidoscopy revealed markedly erythematous, swollen sigmoid mucosal sloughing, involving almost one-third of the lumen at this level.

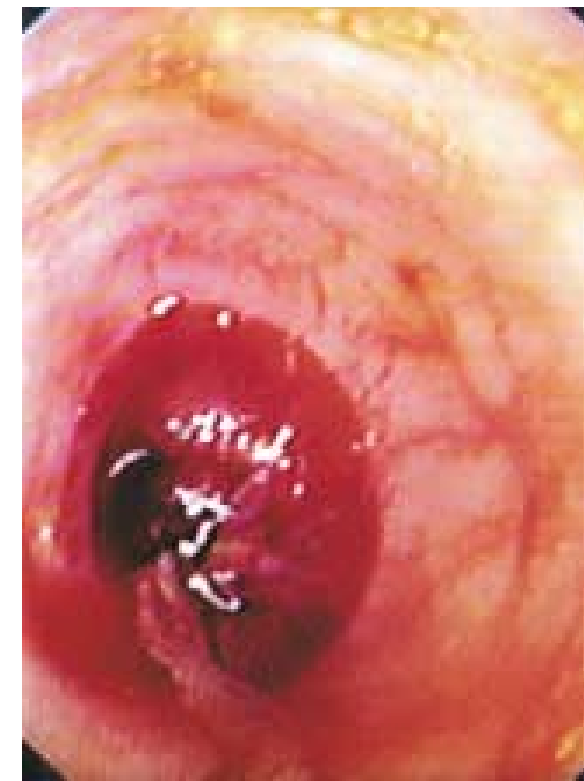

Figure 3 Another rectosigmoidoscopy was performed, showing the lower margin of mucosal dissection at the rectosigmoid junction, circumferential in shape, with well-defined borders and a residual mucosal flap.
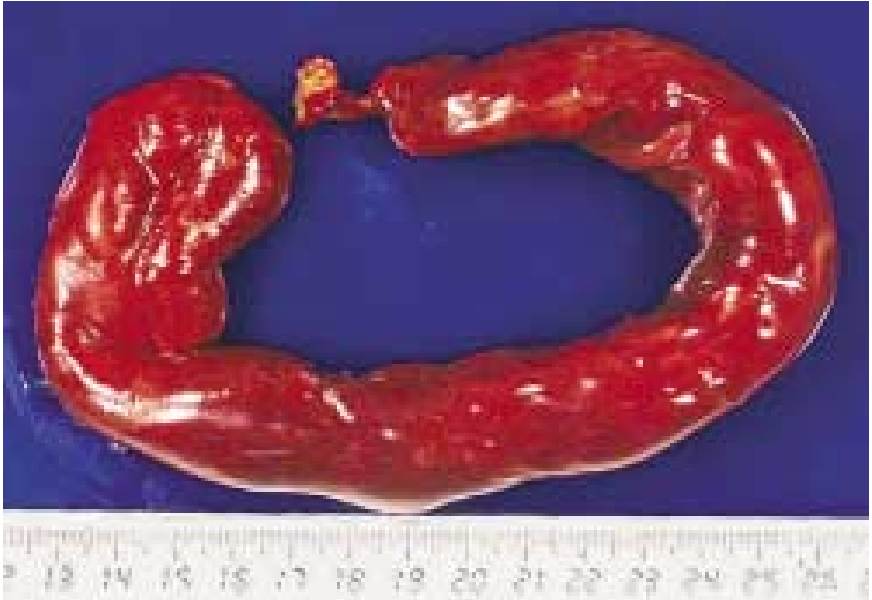

Figure 2 When the sigmoidoscope was removed, the patient expelled a 42-cm long, sausage-like cylindrical structure.

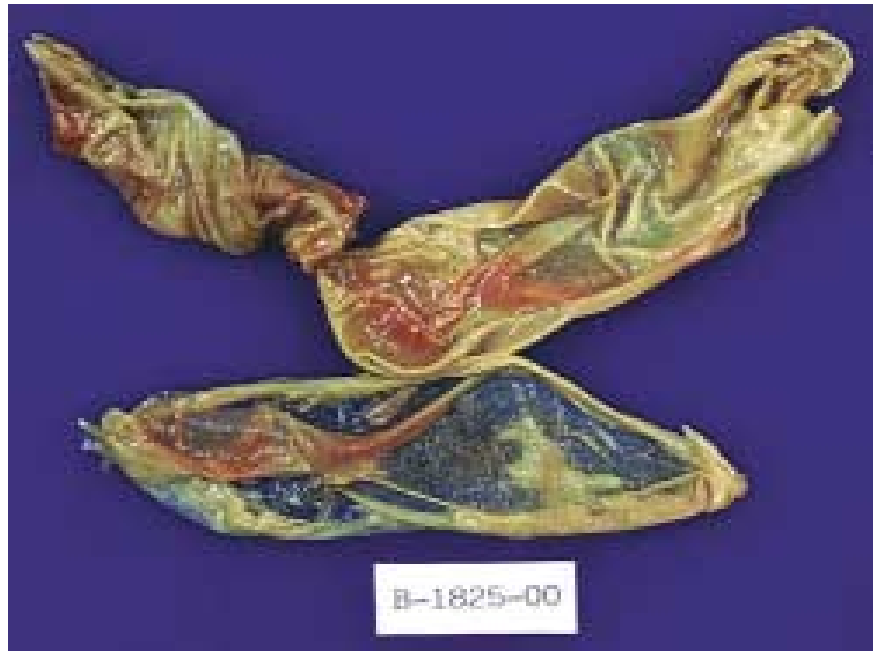

Figure 4 Histopathological evaluation of the specimen after longitudinal incision and cleaning of fecal debris showed normal intestinal epithelium, with connective tissue and scattered inflammatory cells in the lamina propria. 